\title{
ADDITION COMPOUNDS OF METHYL SUBSTITUTED CYCLIC ETHERS WITH BORON TRIFLUORIDE(1)
}

\author{
D. E. McLaughlin*, M. Tamres, S. Searles, JR. and S. Nukina \\ Chemistry Laboratories of The University of Michigan and Kansas State University
}

(Received 18 February 1960; in revised form 4 August 1960)

\begin{abstract}
A manometric method was used to study the addition compounds of boron trifluoride with 2-methyltetrahydrofuran, 2,5-dimethyltetrahydrofuran, 2-methyltetrahydropyran and 2,6-dimethyltetrahydropyran. Physical characteristics are given. Methyl substitution in both tetrahydrofuran and tetrahydropyran causes the addition compound to be more highly dissociated, with the effect being much more pronounced for the latter. In spite of the increased dissociation, the addition compounds formed with the substituted five-membered ring ethers have higher enthalpies and entropies of dissociation than does that formed with the unsubstituted ether. In the six-membered ring system, however, all the thermodynamic values for the dissociation process are largest for the unsubstituted case.
\end{abstract}

STUDIES of the boron trifluoride addition compounds with tetrahydrofuran and tetrahydropyran indicate that the ring size effect rather than steric interaction between the boron trifluoride and the $\alpha$-methylene hydrogen atoms of the cyclic ether seems to be the major factor in accounting for the relative stability of the two complexes, ${ }^{(2)}$ namely, tetrahydrofuran : boron trifluoride $>$ tetrahydropyran :boron trifluoride. Even methyl substitution on the $\alpha$-carbon atom in the cyclic ethers does not produce steric interference in the formation of hydrogen bonds with chloroform or methanol-d, ${ }^{(3)}$ since the normal inductive effect is observed. The same is true in complex formation of 2-methyltetrahydrofuran with the more bulky iodine as compared to tetrahydrofuran itself. ${ }^{(4,5)}$ With a still more bulky acid it is very possible that methyl substitution could cause the steric or "F-strain" effect to overshadow the inductive effect. A quantitative answer to this question was sought by investigating the influence of $\alpha$-methyl substituents on the strength of the linkage and stability of the addition compounds formed between boron trifluoride and the five- and six-membered ring ethers. It is clear that in the absence of steric effects in the $\alpha$-methyl substituted cyclic ethers it would not be possible to invoke "F-strain" as arising from the interaction of boron trifluoride with the $\alpha$-methylene groups in the unsubstituted cyclic ethers.

\section{EXPERIMENTAL}

Materials. The boron trifluoride was the same as that described previously, (8) and the 2-methyltetrahydrofuran was purified as described elsewhere.(1) Synthesis and purification of the other compounds are described below. The purity of each cyclic ether was checked by gas phase chromatography.

- Present address: Department of Chemistry, Augustana College, Rock Island, Illinois.

(1) Taken in part from the Ph.D. Thesis of D. E. MCLAughuin, University of Michigan (1959).

(a) D. E. Mclaughlin, M. Tamres and S. Searles, JR., J. Amer. Chem. Soc. 82, 5621 (1960).

(a) S. Searles and M. TAMres, J. Amer. Chem. Soc. 73, 3704 (1951).

(4) Sister M. Brandon, M. Tamres and S. Searles, JR., J. Amer. Chem. Soc. 82, 2129 (1960).

(5) M. Tamres and Sister M Rrandon, J. Amer. Chem. Soc. 82, 2134 (1960).

(6) D. E. MCLaughinan and M. Tamres, J. Amer. Chem. Soc. 82, 5618 (1960). 
2-Methyltetrahydropyran was prepared by the condensation of 1,3-dibromopropane with acetoacetic ester in the presence of two moles of sodium ethoxide, yielding ethyl 2-methyl-5,6-dihydropyran-3-carboxylate, which was hydrolysed and decarboxylated. ${ }^{(7)}$ The resulting 2-methyl-5,6dihydropyran was distilled over sodium (b.p. $105-106^{\circ}$ (reported $106^{\circ}(7)$ ), yield $38 \%$ ) and reduced by hydrogen at $800 \mathrm{lb} / \mathrm{in}^{2}$ over Raney nickel at $110^{\circ}$, to give 75 per cent of 2-methyltetrahydropyran, b.p. $100-101^{\circ}(740 \mathrm{~mm})$, (reported b.p. $103-104^{\circ}$ at $\left.720 \mathrm{~mm}\right) .{ }^{(7)}$ The dehydration of 1,5-hexanediol with sulphuric acid ${ }^{(7)}$ gave a product of about the same boiling point, but it was shown by gas phase chromatography to be a mixture of two compounds in approximately 60:40 ratio. It is believed that rearrangement occurred to give 2,5-dimethyltetrahydrofuran to a considerable extent.

TABLE 1.-SATURATION PRESSURES OF 2-METHYLTETRAHYDROFURAN:BORON TRIFLUORIDE

\begin{tabular}{|c|c|c|c|c|c|}
\hline \multicolumn{6}{|c|}{$\begin{array}{c}\text { m.p. }-28 \cdot 8--27 \cdot 3^{\circ} \mathrm{C} \\
\text { Saturation pressure equation (liquid): } \\
\log P=\frac{-3291}{T}+10 \cdot 243\end{array}$} \\
\hline Temperature $\left({ }^{\circ} \mathrm{C}\right)$ & $50 \cdot 5$ & $55 \cdot 0$ & 59.9 & $65 \cdot 5$ & $70 \cdot 1$ \\
\hline Pressure (mm) & $1 \cdot 17$ & $1 \cdot 59$ & $2 \cdot 29$ & $3 \cdot 37$ & $4 \cdot 59$ \\
\hline Temperature $\left({ }^{\circ} \mathrm{C}\right)$ & $74 \cdot 9$ & 79.9 & $85 \cdot 1$ & $89 \cdot 8$ & $94 \cdot 6$ \\
\hline Pressure (mm) & $6 \cdot 20$ & $8 \cdot 41$ & $11 \cdot 41$ & $15 \cdot 01$ & $19 \cdot 55$ \\
\hline
\end{tabular}

2,6-Dimethyltetrahydropyran was prepared by a synthetic sequence analogous to that above, starting with 1,3-dibromobutane and acetoacetic ester. ${ }^{(8)}$ The product, obtained in 49 per cent yield, had b.p. $110^{\circ}(735 \mathrm{~mm}), n_{20}^{\mathrm{n}} 1 \cdot 4172$. This material has been synthesized previously by different methods and reported to have b.p. $113 \cdot 5-115^{\circ},{ }^{(9)} 115-117^{\circ(10)}$ and $118^{\circ(\theta)}$, the first being probably the cis compound, the last the trans and the second a mixture of both. Because of the method of reduction and the stable di-axial configuration for the cis isomer, our product is presumed to be cis or mostly cis.

2,5-Dimethyltetrahydrofuran was prepared by hydrogenation of 2,5-dimethylfuran over platinum oxide catalyst at room temperature and 1-2 atmospheres pressure. It had b.p. $91-92^{\circ}$ (740 mm).

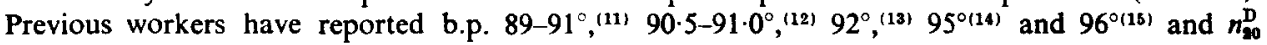
1.4032 , $^{(14)} 1.4043^{(12)}$ and $1.405^{(13)}$ for products which were probably mixtures of the cis and transisomers. Because of the mild conditions for hydrogenation used here, our product is presumed to be the cis isomer.

Apparatus. The manometric unit used in this investigation has been described previously. ${ }^{(8)}$

\section{RESULTS}

2-Methyltetrahydrofuran:boron trifluoride. Boron trifluoride and 2-methyltetrahydrofuran interact to form a stable $1: 1$ addition compound which is a colourless liquid at room temperature but a white solid at low temperatures. The compound melts at $-28 \cdot 8--27 \cdot 3^{\circ}$, lower than that $\left(11 \cdot 7-12 \cdot 3^{\circ}\right)$ for the compound formed with tetrahydrofuran. The saturation pressures in the range studied were slightly greater at corresponding temperatures than those of tetrahydrofuran:boron trifluoride. These data can be found in Table 1 and Fig. 1.

(7) A. LiPP, Ber. Disch. Chem. Ges. 18, 3275 (1885).

(8) R. G. FArgher and W. H. Perkin, J. Chem. Soc. 105, 1353 (1914).

(0) M. Delepine and G. Amiard, $C$. $R$. Acad. Sci., Paris 215, 309 (1942).

(10) M. BAdoche, Ann. Chim. 19, 405 (1944).

(11) J. Clode and F. Pilgrim, J. Amer. Chem. Soc. 61, 2667 (1939).

(12) E. V. Whitehead, R. A. Dean and F. A. Fidler, J. Amer. Chem. Soc. 73, 3632 (1951).

(13) J. Colonge and A. LAGier, Bull. Soc. Chim. Fr. 27, (1949).

(11) Y. K. Yurev, V. A. Tronova, N. A. Lvova and Z. YA. Bukshpan, J. Gen. Chem. (U.S.S.R.) 11, 1128 (1941).

(16) A. Kirrmann and N. Hamaide, Bull. Soc. Chim. Fr. 789 (1957). 
Dissociation pressure data for this addition compound can be found in Table 2 and Fig. 2.

2-Methyltetrahydropyran:boron trifluoride. Boron trifluoride interacts with 2-methyltetrahydropyran to form a colourless liquid $1: 1$ addition compound at room temperature. The compound is a white solid at low temperatures and melts at -7 $-6^{\circ}$, which is lower than that $\left(9 \cdot 5-10 \cdot 2^{\circ}\right)$ for the addition compound formed with

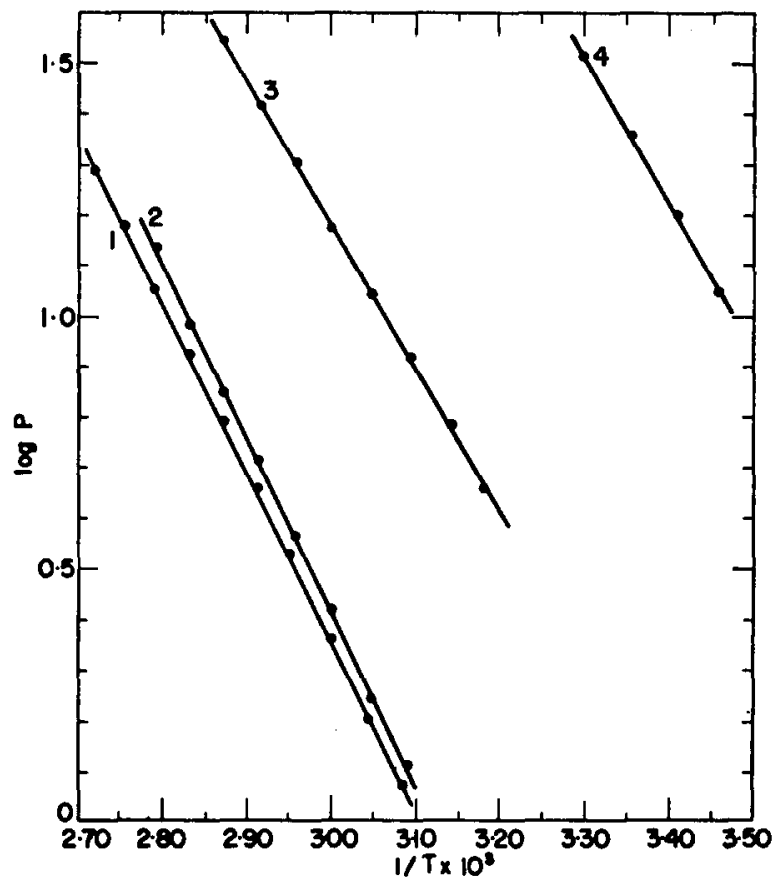

FIG. 1. - Saturation pressure data for the metyhl substituted cyclic ether:boron trifluoride addition compounds.

1. 2-Methyltetrahydrofuran:boron trifluoride (liquid)

2. 2,5-Dimethyltetrahydrofuran:boron trifluoride (liquid)

3. 2-Methyltetrahydropyran:boron trifluoride (liquid)

4. 2,6-Dimethyltetrahydropyran :boron trifluoride (solid).

tetrahydropyran. The saturation pressures were greater at corresponding temperatures than those for tetrahydropyran:boron trifluoride. These data can be found in Table 3 and Fig. 1.

Dissociation pressure data for this addition compound can be found in Table 4 and Fig. 2.

2,5-Dimethyltetrahydrofuran:boron trifluoride. The addition compound of boron trifluoride with 2,5-dimethyltetrahydrofuran is a white solid at temperatures somewhat below room temperature and melts to give a colourless liquid. The observed melting point is $23-24^{\circ}$. Some instability of this addition compound was observed in the gas phase studies above $100^{\circ}$, but no decomposition of the material at room temperature was noted over periods of several days. In making saturation pressure measurements, it was observed that prolonged heating at $120^{\circ}$ resulted in an increase in the apparent saturation pressures in the temperature range 50-90. Saturation pressures taken witiout subjecting the compound to temperatures above $90^{\circ}$ are 
TABLE 2.-DISSOCIATION DATA FOR 2-METHYLTETRAHYDROFURAN:BORON TRIFLUORIDE

\begin{tabular}{ccc}
\hline $\begin{array}{c}\text { Temperature } \\
\left({ }^{\circ} \mathrm{C}\right)\end{array}$ & $\begin{array}{c}\text { Pressure } \\
(\mathrm{mm})\end{array}$ & $\begin{array}{c}\text { Dissociation constant } \\
K(\mathrm{~atm})\end{array}$ \\
\hline \multicolumn{3}{c}{$8.230 \mathrm{~mm} \mathrm{BF}_{\mathrm{a}}$ and $8.434 \mathrm{~mm} \mathrm{2-methyltetrahydrofuran} \mathrm{at} 0^{\circ} \mathrm{C}$} \\
& $\log K=\frac{-3921}{T}+8.892$ \\
106.2 & 18.672 & 0.0187 \\
104.9 & 19.337 & 0.0243 \\
109.8 & 20.112 & 0.0328 \\
114.9 & 20.893 & 0.0452 \\
119.8 & 21.585 & 0.0599 \\
124.9 & 22.285 & 0.0828 \\
\end{tabular}

$7.947 \mathrm{~mm} \mathrm{BF}_{8}$ and $8.103 \mathrm{~mm}$ 2-methyltetrahydrofuran at $0^{\circ} \mathrm{C}$

$$
\log K=\frac{-3873}{T}+8.757
$$

$\begin{array}{rll}95.1 & 17.848 & 0.0172 \\ 99.9 & 18.658 & 0.0239 \\ 104.9 & 19.420 & 0.0326 \\ 104.9 & 19.431 & 0.0328 \\ 109.8 & 20.185 & 0.0453 \\ 114.9 & 20.830 & 0.0594 \\ 119.8 & 21.445 & 0.0785 \\ 124.5 & 22.017 & 0.104 \\ 130.7 & 22.687 & 0.148\end{array}$

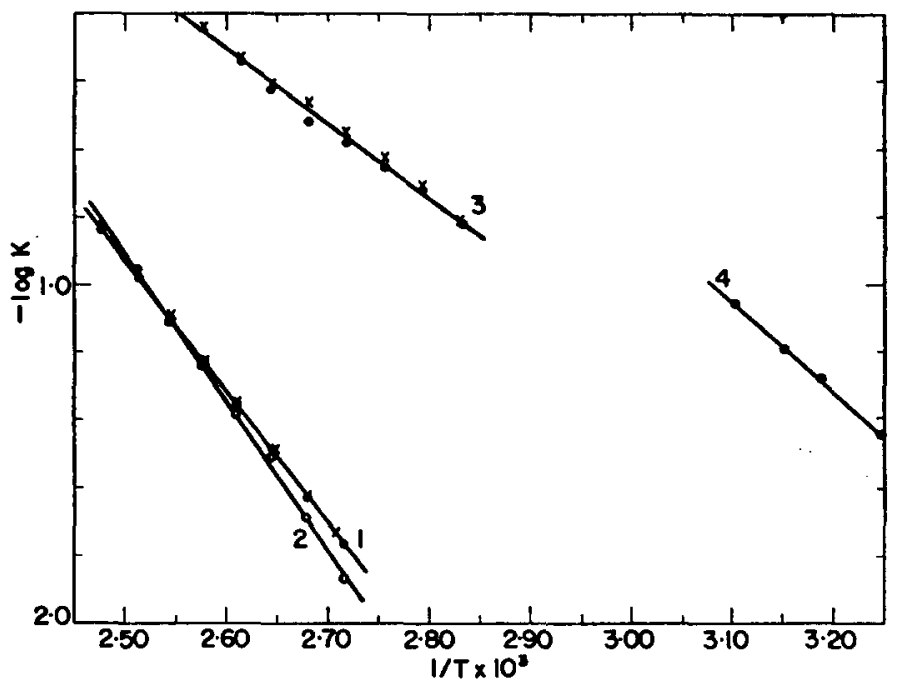

FIG. 2.- $-\log K$ vs. $1 / T$ for the methyl substituted cyclic ether:boron trifluoride addition compounds.

1. $\times 8.434 \mathrm{~mm} \mathrm{2-methyltetrahydrofuran} \mathrm{and} 8.230 \mathrm{~mm} \mathrm{BF}$

- $8.103 \mathrm{~mm} \mathrm{2-methyltetrahydrofuran} \mathrm{and} 7.947 \mathrm{~mm} \mathrm{BF_{2 }}$

2. $8.323 \mathrm{~mm} 2,5$-dimethyltetrahydrofuran and $8.216 \mathrm{~mm} \mathrm{BF}_{8}$

3. $12.936 \mathrm{~mm}$ 2-methyltetrahydropyran and $12.537 \mathrm{~mm} \mathrm{BF}_{3}$

$\times 15.156 \mathrm{~mm}$ 2-methyltetrahydropyran and $15.411 \mathrm{~mm} \mathrm{BF}_{3}$

4. $13.300 \mathrm{~mm} \mathrm{2,6-dimethyltetrahydropyran} \mathrm{and} \mathrm{14.094} \mathrm{mm} \mathrm{BF}$, 
TABLE 3.-SATURATION PRESSURES OF 2-METHYLTETRAHYDROPYRAN:BORON TRIFLUORIDE

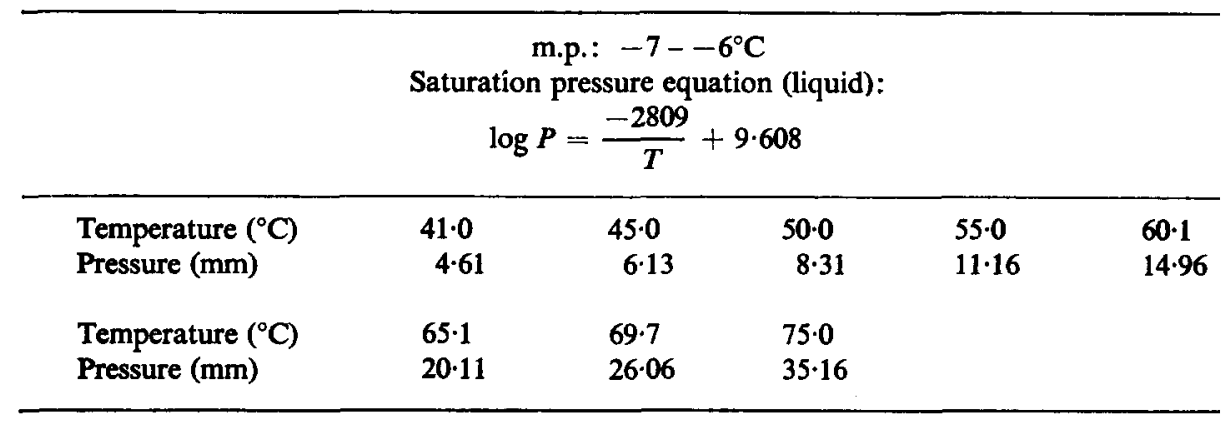

TABLE 4.-DISSOCIATION DATA FOR 2-METHYLTETRAHYDROPYRAN:BORON TRIFLUORIDE

\begin{tabular}{ccc}
\hline $\begin{array}{c}\text { Temperature } \\
\left({ }^{\circ} \mathrm{C}\right)\end{array}$ & $\begin{array}{c}\text { Pressure } \\
(\mathrm{mm})\end{array}$ & $\begin{array}{c}\text { Dissociation constant } \\
K \text { (atm) }\end{array}$ \\
\hline \multicolumn{3}{c}{$12.537 \mathrm{~mm} \mathrm{BF}_{3}$ and $12.936 \mathrm{~mm} 2$-methyltetrahydropyran at $0^{\circ} \mathrm{C}$} \\
79.8 & $\log K=\frac{-2107}{T}+5 \cdot 149$ \\
84.8 & 31.057 & 0.151 \\
89.7 & 31.791 & 0.191 \\
94.5 & 32.418 & 0.223 \\
99.7 & 33.109 & 0.260 \\
105.2 & 33.615 & 0.300 \\
109.5 & 34.320 & 0.381 \\
\end{tabular}

$15.411 \mathrm{~mm} \mathrm{BF}_{\mathrm{s}}$ and $15.156 \mathrm{~mm}$ 2-methyltetrahydropyran at $0^{\circ} \mathrm{C}$

$$
\log K=\frac{-2167}{T}+5 \cdot 344
$$

$\begin{array}{rrr}80.1 & 37.000 & 0.158 \\ 84.8 & 37.921 & 0.198 \\ 89.7 & 38.731 & 0.239 \\ 94.7 & 39.486 & 0.281 \\ 99.7 & 40.296 & 0.348 \\ 104.7 & 40.972 & 0.395 \\ 109.5 & 41.679 & 0.475 \\ 115.0 & 42.460 & 0.580\end{array}$

TABLE 5.-SATURATION PRESSURES OF 2,5-DIMETHYLTETRAHYDROFURAN:BORON TRIFLUORIDE

m.p.: $23-24^{\circ} \mathrm{C}$

Saturation pressure equation (liquid):

\begin{tabular}{lccccc}
\multicolumn{6}{c}{$\log P=\frac{-3419}{T}+10.678$} \\
Temperature $\left({ }^{\circ} \mathrm{C}\right)$ & 50.2 & 54.8 & 59.9 & 64.8 & 69.9 \\
Pressure $(\mathrm{mm})$ & 1.30 & 1.75 & 2.62 & 3.68 & 5.22 \\
& & & & & \\
Temperature $\left({ }^{\circ} \mathrm{C}\right)$ & 74.8 & 79.9 & 84.8 & 89.8 & \\
Pressure $(\mathrm{mm})$ & 7.11 & 9.66 & 13.72 & 18.20 & \\
\hline
\end{tabular}


given in Table 5 and Fig. 1. Again they are higher at comparable temperatures than those of either tetrahydrofuran:boron trifluoride ${ }^{(2)}$ or 2 -methyltetrahydrofuran :boron trifluoride.

In the dissociation studies, the onset of an irreversible reaction was noted by the slow change in the dissociation constant with time at a given temperature. The change was sufficiently slow to permit accurate determination of the dissociation data. These are presented in Table 6 and Fig. 2.

2,6-Dimethyltetrahydropyran:boron trifluoride. The freshly prepared addition compound of 2,6-dimethyltetrahydropyran with boron trifluoride is a white solid at

TABLE 6.-DISSOCIATION DATA FOR 2,5-DIMETHYLTETRAMYDROFURAN:BORON TRIFLUORIDE

\begin{tabular}{|c|c|c|}
\hline & $\log K \cdot \frac{-4327}{T}+9 \cdot 908$ & \\
\hline $\begin{array}{l}\text { Temperature } \\
\text { (C) }\end{array}$ & $\begin{array}{c}\text { Pressure } \\
(\mathrm{mm})\end{array}$ & $\begin{array}{c}\text { Dissociation constant } \\
K(\mathrm{~atm})\end{array}$ \\
\hline \multicolumn{3}{|c|}{$8.216 \mathrm{~mm} \mathrm{BF}_{3}$ and $8.323 \mathrm{~mm}$ of 2,5 -dimethyltetrahydrofuran at $0^{\circ} \mathrm{C}$} \\
\hline $95 \cdot 0$ & $17 \cdot 887$ & 0.0136 \\
\hline $100 \cdot 0$ & $18 \cdot 901$ & 0.0206 \\
\hline $105 \cdot 0$ & $19 \cdot 885$ & 0.0311 \\
\hline $110 \cdot 0$ & $20-627$ & 0.0417 \\
\hline $115 \cdot 0$ & $21 \cdot 388$ & 0.0578 \\
\hline $120 \cdot 0$ & 22.067 & 0.0783 \\
\hline $124 \cdot 9$ & $22 \cdot 757$ & $0 \cdot 112$ \\
\hline $130 \cdot 6$ & $23 \cdot 365$ & $0 \cdot 151$ \\
\hline
\end{tabular}

room temperature and melts in the range $28-35^{\circ}$ to give a colourless liquid. This compound was observed to undergo decomposition at room temperature over a period of several days to give an amber coloured liquid. After fractionation of this liquid, a residue of a colourless, nonvolatile liquid remained which could not be moved in the vacuum line under high vacuum. The wide melting range of the freshly prepared compound could not be attributed to decomposition nor could it be attributed to an impure sample of the ether since gas phase chromatography had verified its purity. There is considerable dissociation of the vapour at the melting temperature, and perhaps the complex in the liquid state is also somewhat dissociated, a condition known to cause a wide melting range. ${ }^{(16)}$ Another possible explanation is that the mixture of cis and trans isomers which are possible in such a disubstituted ring system is causing the wide melting range. Some saturation pressures of the freshly prepared addition compound are presented in Table 7 and Fig. 1.

In the interaction of boron trifluoride with 2,6-dimethyltetrahydropyran, a secondary, irreversible reaction occurred which was sufficiently rapid so that reliable dissociation data could be obtained only within the first one and a half hours after bringing the two components together, after which the pressure was observed to increase slowly for a short time and thereafter to decrease. A nonvolatile liquid residue remained in the reaction vessel which necessitated a thorough cleaning before further experimental work. Fortunately, the experimental apparatus of this investigation permitted rapid measurement of dissociation pressures, and it was possible to 
obtain several measurements at various temperatures before the onset of the secondary reaction. The dissociation data for this addition compound can be found in Table 8 and Fig. 2.

\section{DISCUSSION}

The thermodynamic values derived from the dissociation data are summarized in Table 9. The values for tetrahydrofuran:boron trifluoride and tetrahydropyran:boron trifluoride are included ${ }^{(2)}$ for purposes of comparison. The larger experimental errors assigned to the thermodynamic values for 2,5-dimethyltetrahydrofuran and

TABLE 7.-SATURATION PRESSURES OF 2,6-DIMETHYLTETRAHYDROPYRAN:BORON TRIFLUORIE

\begin{tabular}{lcccc}
\hline \multicolumn{4}{c}{ m.p.: $28-35^{\circ} \mathrm{C}}$. \\
& Saturation pressure equation (solid): & \\
& $\log P=\frac{-2861}{T}+10.957$ & \\
\hline Temperature $\left({ }^{\circ} \mathrm{C}\right)$ & 15.8 & 20.0 & 24.9 & 30.0 \\
Pressure (mm) & 11.4 & 16.0 & 23.1 & 33.0 \\
\hline
\end{tabular}

TABLE 8.-DISSOCIATION DATA FOR 2,6-DIMETHYLTETRAHYDROPYRAN:BORON TRIFLUORIDE

\begin{tabular}{ccc} 
& $\log K=\frac{-2610}{T}+7.045$ & \\
$\begin{array}{c}\text { Temperature } \\
\left({ }^{\circ} \mathrm{C}\right)\end{array}$ & $\begin{array}{c}\text { Pressure } \\
(\mathrm{mm})\end{array}$ & $\begin{array}{c}\text { Dissociation constant } \\
K \text { (atm) }\end{array}$ \\
\hline $14.094 \mathrm{~mm} \mathrm{BF}_{3}$ and $13.300 \mathrm{~mm} \mathrm{2,6-dimethyltetrahydropyran} \mathrm{at} 0^{\circ} \mathrm{C}$ \\
34.6 & 26.382 & 0.0364 \\
40.2 & 27.797 & 0.0529 \\
44.1 & 28.569 & 0.0649 \\
49.1 & 29.585 & 0.0884 \\
\hline
\end{tabular}

2,6-dimethyltetrahydropyran are due to the experimental difficulty with irreversible reaction which was encountered for these two cases, particularly the latter.

The thermodynamic data of Table 9 show that methyl substitution on the $\alpha$-carbon atoms of the five-membered ring ether results in a higher enthalpy of dissociation for the addition compound with boron trifluoride. If the enthalpy value is taken as a measure of the strength of interaction between boron trifluoride and the ether, its increase with methyl substitution must reflect an increased electron density on the oxygen atom due to the normal inductive effect.

This enhancement of electron donor ability upon $\alpha$-methyl substitution has been reported in hydrogen bonding studies on the cyclic ethers. ${ }^{(3)}$ A more quantitative measure of the effect can be made by comparing the iodine complexes with tetrahydrofuran and with 2-methyltetrahydrofuran. $(4,5)$ The thermodynamic values for dissociation of ide former are $\Delta H^{\circ}=5.3 \mathrm{kcal} / \mathrm{mole}, \Delta F_{25}^{\circ}=1.70 \mathrm{kcal} / \mathrm{mole}$, and $\Delta S^{\circ}=11.6$ e.u., while those for the latter are $\Delta H^{\circ}=6.2 \mathrm{kcal} / \mathrm{mole}, \Delta F_{25}^{\circ}=1.84$ $\mathrm{kcal} / \mathrm{mole}$, and $\Delta S^{\circ}=14.6 \mathrm{e}$.u. In these studies, where steric effects were judged to be small, there is an increase in all the thermodynamic functions. 
However, this is not the case for the boron trifluoride addition compounds of the cyclic ethers studied here. Introduction of one methyl group in the five-membered ring ether causes about $1 \mathrm{kcal}$ increase in $\Delta H^{\circ}$ but about a $0.4 \mathrm{kcal}$ decrease in $\Delta F^{\circ}$, while in the six-membered ring ether the corresponding change causes a decrease in both $\Delta H^{\circ}$ and $\Delta F^{\circ}$, amounting to 5.6 and $1.7 \mathrm{kcal}$, respectively. This, of course, points to the presence of steric repulsive forces in the addition compounds, and there is similarity to the case of acyclic ethers, in which $\Delta F^{\circ}$ decreases by $0.6-0.9 \mathrm{kcal}$ per $\alpha$-methyl group in the series: methyl ether, ethyl ether, isopropyl ether. ${ }^{(17)}$

TABLE 9.-THERMODYNAMIC DISSOCIATION DATA FOR ADDITION COMPOUNDS OF METHYL SUBSTITUTED CYCLIC ETHERS WITH BORON TRIFLUORIDE

\begin{tabular}{|c|c|c|c|c|}
\hline & $\begin{array}{c}\Delta H^{\circ} \\
\text { (kcal/mole) }\end{array}$ & $\begin{array}{c}K_{100} \\
(\mathrm{~atm})\end{array}$ & $\begin{array}{c}\Delta F_{100}^{\circ} \\
\text { (cal } / \text { mole })\end{array}$ & $\begin{array}{c}\Delta S^{\circ} \\
\text { (e.u.) }\end{array}$ \\
\hline Tetrahydrofuran: $\mathbf{B F}_{\mathbf{3}}$ & $16.80 \pm 0.2$ & 0.0144 & $3145 \pm 20$ & $36.6 \pm 0.6$ \\
\hline 2-Methyltetrahydrofuran: $\mathrm{BF}_{\mathrm{s}}$ & $17 \cdot 83 \pm 0 \cdot 2$ & 0.0241 & $2763 \pm 20$ & $40.4 \pm 0.6$ \\
\hline 2,5-Dimethyltetrahydrofuran: $\mathrm{BF}_{3}$ & $19.80 \pm 0.5$ & 0.0206 & $2879 \pm 40$ & $45 \cdot 3 \pm 1 \cdot 5$ \\
\hline Tetrahydropyran: $\mathbf{B F}_{\mathbf{3}}$ & $15.42 \pm 0.2$ & 0.0339 & $2510 \pm 20$ & $34.6 \pm 0.6$ \\
\hline 2-Methyltetrahydropyran $: \mathrm{BF}_{3}$ & $9.78 \pm 0.3$ & 0.332 & $818 \pm 30$ & $24.0 \pm 0.9$ \\
\hline 2,6-Dimethyltetrahydropyran: $\mathrm{BF}_{3}$ & $11.9 \pm 1$ & $1 \cdot 13$ & $-87 \pm 80$ & $32 \cdot 2 \pm 3$ \\
\hline
\end{tabular}

In the five-membered ring, apparently the steric repulsion is small enough to permit the approach of the boron atom close enough for strong interaction, only with a very restricted orientation of the two species relative to each other. This is reflected in the large increase in the entropy of dissociation. In the six-membered ring, however, the $\alpha$-methyl group gives considerably more interference so that no such rigid orientation is possible-only a weak association with considerably more freedom in each of the species than in the unsubstituted case.

In each ring size, introduction of the second methyl group at the other $\alpha$-carbon atom caused an increase of about $2 \mathrm{kcal}$ in the interaction with boron trifluoride, compared to the monomethyl derivative, and also an increase in entropy was observed for each. This would imply that the steric repulsion was less than the electronic advantage for the second methyl group, so that a stronger association with greater rigidity resulted. Further comparison is difficult because at least one of these compounds was probably a mixture of cis and trans isomers, which probably interact somewhat differently with boron trifluoride.

Acknowledgements-This research was supported in part by a grant from the Petroleum Research Fund administered by the American Chemical Society. Grateful acknowledgement is hereby made to the donors of said fund. One of us (D. E. M.) wishes to express his appreciation to both the Horace H. Rackham School of Graduate Studies of The University of Michigan and the Allied Chemical Corporation for fellowships.

(17) H. C. Brown and R. M. Adaus, J. Amer. Chem. Soc. 64, 2557 (1944). 